EESTI NSV TEAdUSTE AKADEEMIA TOIMETISED. 31. KOIDE

FOOSIKA * MATEMAATIKA. 1982, NR. 3

ИЗВЕСТИЯ АКАДЕМИИ НАУК ЭСТОНСКОП ССР. ТОМ 31 ФИЗИКА * МАТЕМАТИКА, 1982, № 3

\title{
T. TOBIAS
}

\section{IDENTIFICATION OF THE DIFFUSION PROCESS AND INVERSE PARABOLIC PROBLEMS}

\author{
(Presented by N. Alumäe)
}

Let $x_{t}$ be a $d$-dimensional diffusion process controlled by the equation $d x_{t}=b(x, \theta) d t+\sigma(x, \theta) d w_{t}, \quad x(0)=x_{0}$. The coefficients of the equation are dependent on the unknown parameter $\theta$. Usually in estimation problems it is supposed that the trajectory $x_{s}, 0<s \leqslant T$, is observable at every moment $s$ and then the estimate $\hat{\theta}$ can depend on the whole trajectory $x_{s}, 0<s \leqslant T$.

In this work we shall consider a different model. Various trajectories of the process are observable only at separate random moments connected with the exit time of the process from the given region. For example, the observations can be the time intervals during which the various trajectories of the process have reached the boundary. Inside the region the trajectories are not observable. The observations on the boundary can be used for approximating certain functionals depending on the trajectories of the process and thus it is possible to estimate $\theta$ itself.

Such a problem was set up at $\left.{ }^{[}{ }^{1}\right]$ where some examples were given, permitting to derive analytical solutions.

In this paper we shall derive some approximate methods to estimate $\theta$ in more general models.

1. Let $x_{t}$ be the homogeneous diffusion process with strictly elliptic infinitesimal operator $L=\sum_{i, j=1}^{d} a_{i j}(x, \theta) \frac{\partial^{2}}{\partial x_{i} \partial x_{j}}+\sum_{i=1}^{d} b_{i}(x, \theta) \frac{\partial}{\partial x_{i}}$ with smooth coefficients $a_{i j}(x, \theta)$ and $b_{i}(x, \theta)$. Let $D \subset R^{d}$ be a bounded set with smooth boundary $\Gamma$ and let $\gamma \subset \Gamma$. Let $u_{\gamma}(t, x)$ be the probability that $x(s), 0<s \leqslant t, x(0)=x$ has reached the boundary $\gamma$ during the time $t$. It is known [ $\left.{ }^{2}\right]$ that $u=u_{\gamma}(t, x)$ is the solution of the equation

$$
\begin{gathered}
\frac{\partial u}{\partial t}=L u, \\
u(0, x)=0, \quad u(t, x)=1, \quad x \in \gamma, \quad u(t, x)=0, \quad x \in \Gamma \backslash \gamma .
\end{gathered}
$$

Suppose that it is possible to estimate the function $u(t, x)$. For example, suppose that over trajectory we can only determine if it has reached the boundary $\gamma$ during the time $t$ or not. If from $N$ trajectories $k(t, x)$ has reached $\gamma$ during $t$, then $u_{N}(t, x)=k(t, x) / N \approx u(t, x)$ and $\lim u_{N}(t, x)=u(t, x)$ with probability 1 for $x \in D$. Now the estimating problem can be stated as follows: given the estimate of the solution of the equation (1), find the estimates for the coefficients $a_{i j}(x)$ and $b_{i}(x)$ in nonparametric case or find the estimate for the parameter $\theta$ in parametric case.

The given model corresponds to the situation when the process is observable only on the part $\gamma$ of the boundary $\Gamma$. 
In such a setting the problem is closely connected with the inverse problems in differential equations $\left[{ }^{3,4}\right]$. These inverse problems we shall treat as certain deterministic control problems. Such a point of view is well known. In the control theory for partial differential equations this method was used mainly in linear cases where the control (estimated parameter) contained in the right-hand side of the equation or in the initial (boundary) conditions of the equation [5]. The problem with the control in the coefficients is more complicated $\left[{ }^{5,6}\right]$ and the approximative methods are considered mainly in the case of equations with constant coefficients [ $\left.{ }^{7}\right]$.

We shall learn the parametric case and in order to simplify the notations, only one-dimensional case is treated. We suppose that $a(x, \theta)=$ $=\sum_{i=1}^{n} \theta_{i} a_{i}(x)$ and $b(x, \theta) \equiv 0$. All the results and methods can be generalized without changes to the case $x \in R^{d}$ for estimating the parametrized functions $a_{i j}(x, \theta)$ and $b_{i}(x, \theta)$.

2. Let $a_{1}(x)>0, \ldots, a_{n}(x)>0$ be linearly independent functions on the interval. $x \in[0,1]$. Denote $a^{\prime}=\left(a_{1}, \ldots, a_{n}\right), \theta^{\prime}=\left(\theta_{1}, \ldots, \theta_{n}\right)$. and $(\theta, a)=\sum_{i=1}^{n} \theta_{i} a_{i}(x)$. Let us consider the equation

$$
\begin{gathered}
u_{t}-(\theta, a) u_{x x}=0, \\
u(0, x)=0, \quad u(t, 0)=1, \quad u(t, 1)=0 .
\end{gathered}
$$

Suppose that $\theta \in M$, where $M \subset R^{n}$ is a bounded closed set. Suppose that $a_{i}(x), x \in[0,1]$ satisfy the Hölder condition with degree $\alpha$, i.e. $a_{i}(x) \in C_{\alpha}$. Let $(\theta, a) \geqslant c>0, \theta \in M, x \in[0,1]$. It is known [ $\left.{ }^{8}\right]$ that the equation (2), (3) has the unique solution and inside the region $D_{T}=$ $=[0, T] \times[0,1] u \in C_{2+\alpha}$. If $\theta_{m} \rightarrow \theta$ then $u_{m}=u_{m}\left(t, x ; \theta_{m}\right),\left(u_{m}\right)_{t},\left(u_{m}\right)_{x}$ and $\left(u_{m}\right)_{x x}$ converge to $u=u(t, x ; \theta), u_{t}, u_{x}$ and $u_{x x}$ uniformly on every open subregion of $D_{T}$.

Let $\bar{u}=u(t, \bar{x} ; \theta)=z_{N}(t)+\varepsilon_{N}(t)$, where $u(t, \bar{x} ; \theta)$ is the probability that trajectory of the diffusion process $x_{s}, 0<s \leqslant t, x(0)=\bar{x}$, has reached the boundary $x=0$ during the time $t$ and let $z_{N}(t)$ be the estimate of this probability obtained from $N$ observations. If $k(t, x)$ from $N$ trajectories has reached the boundary $x=0$ during $t$ then $z_{N}(t)=k(t, \bar{x}) / N$ and the error $\varepsilon_{N}(t)$ has asymptotically normal distribution with zero mean.

Suppose that $z_{N}(t)=z(t)$ is fixed. Let

$$
J(\theta)=\int_{0}^{T}[u(t, \bar{x} ; \theta)-z(t)]^{2} d t .
$$

The problem is to find $\theta \in M$ so that $J(\theta) \rightarrow$ min. Evidently, there exists $\theta^{*} \in M$ such that $\min _{\theta \in M} J(\theta)=J\left(\theta^{*}\right)$.

Remark 1. If $M$ is unbounded, then $\theta^{*}$ need not exist. For example, let $u_{t}-\theta u_{x x}=0$ with conditions (3) and let $z(t) \equiv 1$. If $\theta_{n}$ is the minimizing sequence, then $\theta_{n} \rightarrow \infty$.

3. To solve the problem (to find the optimal $\theta^{*}$ ) it is necessary to use some approximative numerical method. Corresponding effective procedures, as a rule, use the gradient of the function $J(\theta)$. We shall derive the exact expression for the $(\operatorname{grad} J(\theta), \Delta \theta)=\sum_{i=1}^{n} \frac{\partial J(\theta)}{\partial \theta_{i}} \Delta \theta_{i}$. 
Lemma 1. Denote $v_{i}=v_{i}(t, x ; \theta)=\frac{\partial u(t, x ; \theta)}{\partial \theta_{i}}$. Then $v_{i}(t, x ; \hat{\theta})$ exists and satisfies the equation:

$$
\begin{array}{ll} 
& \left(v_{i}\right)_{t}-(\theta, a)\left(v_{i}\right)_{x x}=a_{i} u_{x x}, \\
v_{i}(0, x ; \theta)=0 ; \quad v_{i}(t, 0 ; \theta)=v_{i}(t, 1 ; \theta)=0, \quad i=1, \ldots, n .
\end{array}
$$

Denote by $u^{\Delta}(t, x ; \theta)$ the solution of the equation $u_{\iota}^{\Delta}-(\theta+\Delta \theta, a) u_{x x}^{\Delta}=0$ with the conditions (3). Let $v_{i}^{\Delta}=\left(u^{\Delta}-u\right) / \Delta \theta_{i}$, then

$$
\begin{gathered}
\left(v_{i}^{\Delta}\right)_{t}-(\theta, a)\left(v_{i}^{\Delta}\right)_{x x}=\frac{(\Delta \theta, a)}{\Delta \theta_{i}} u_{x x}^{\Delta}, \\
v_{i}^{\Delta}(0, x)=0, \quad v_{i}^{\Delta}(t, 0)=v_{i}^{\Delta}(t, 1)=0 .
\end{gathered}
$$

If $\Delta \theta \rightarrow 0$, then $u_{x x}^{\Delta}$ converges uniformly to $u_{x x}$ in every open subregion of $[0,1]$ and thus $v_{i}^{\Delta}$ with corresponding derivatives converges uniformly $\left[{ }^{8}\right]$. This proves the lemma.

It is easy to see that $\operatorname{grad} J(\theta)=2 \int_{0}^{T}[u(t, \bar{x} ; \theta)-z(t)] v(t, \bar{x} ; \theta) d t$, where $v^{\prime}(t, x ; \theta)=\left(v_{1}, \ldots, v_{n}\right)$.

Let us transform this expression.

Let $p=p(t, x ; \theta)$ be the solution of the conjugate equation:

$$
\begin{gathered}
-\frac{\partial p}{\partial t}-\frac{\partial^{2}}{\partial x^{2}}[(\theta, a) p]=2[u(t, x ; \theta)-z(t)] \delta(x-\bar{x}), \\
p(T, x ; \theta)=0, \quad p(t, 0 ; \theta)=p(t, 1 ; \theta)=0,
\end{gathered}
$$

where $\delta(x-\bar{x})$ is $\delta$-function. By multiplying the equation (6) with the vector $v(t, x ; \theta)$ and integrating each component over the region $D_{T}$, we get (using the equation (4)) :

$$
\begin{gathered}
\operatorname{grad} J(\theta)=\int_{0}^{T} \int_{0}^{1}\left[v_{t}-(\theta, a) v_{x x}\right] p d x d t= \\
=\int_{0}^{T} \int_{0}^{1} a(x) u_{x x}(t, x ; \theta) p(t, x ; \theta) d x d t .
\end{gathered}
$$

Finally:

$$
(\operatorname{grad} J(\theta), \Delta \theta)=\sum_{i=1}^{n} \int_{0}^{T} \int_{0}^{1} p(t, x ; \theta) u_{x x}(t, x ; \theta) a_{i}(x) d x d t \Delta \theta_{i},
$$

where $u(t, x ; \theta)$ and $p(t, x ; \theta)$ are the solutions of the equations (2), (3) and $(6)$.

By means of the expression (7) we can construct various numerical procedures to minimize the function $J(\theta)$.

Remark 2. Such a method for calculating the gradient by using the conjugate equations is known and was used, for example, in $\left[{ }^{6}\right]$.

4. Let us consider the identifiability of the parameter $\theta$. Suppose that the values of the function $u=u(t, x ; \theta)$ are known at fixed points $\left(t_{1}, \bar{x}\right), \ldots,\left(t_{n}, \bar{x}\right)$, i. e. the values $u_{1}=u_{1}\left(t_{1}, \bar{x} ; \theta\right), \ldots, u_{n}=u_{n}\left(t_{n}, \bar{x} ; \theta\right)$ are known. The corresponding Jacobian is

$$
D\left(u_{1}, \ldots, u_{n}\right)=\left|\begin{array}{ccc}
v_{1}\left(t_{1}, \bar{x} ; \theta\right) & \ldots & v_{n}\left(t_{1}, \bar{x} ; \theta\right) \\
v_{1}\left(t_{n}, \bar{x} ; \dot{\theta}\right) & \ldots & v_{n}\left(\dot{t_{n}}, \dot{\bar{x}} ; \dot{\theta}\right)
\end{array}\right| .
$$


If $D\left(u_{1}, \ldots, u_{n}\right) \neq 0$, then $\theta$ is identifiable.

The functions $v_{1}, \ldots, v_{n}$ are independent in the whole region $D_{T}$ because $a_{1}(x), \ldots, a_{n}(x)$ are independent. But in certain subregion they may be dependent and therefore, in general, the values $u_{1}, \ldots, u_{n}$ do not determine the parameter $\theta$.

Consider the special case $n=1$. Let

$$
\begin{aligned}
& u_{t}-\left(a_{0}(x)+\theta a_{1}(x)\right) u_{x x}=0, \\
& u(0, x)=0, u(t, 0)=1, u(t, 1)=0,
\end{aligned}
$$

where $a_{0}(x)>0$ and $a_{1}(x)>0$ are known functions and $\theta$ is an unknown parameter. $a_{0}(x)$ can be interprcted as the approximate value of the unknown function $a(x)$ and $a_{1}(x)$ is the correction.

Lemma 2. For every $t \in(0, T)$ and $\bar{x} \in(0,1)$ the value $u=u(t, \bar{x} ; \theta)$ determines the parameter $\theta$ uniquely.

The function $v(t, x ; \theta)=\frac{\partial u}{\partial \theta}$ satisfies the equation

$$
\begin{gathered}
v_{t}-\left(a_{0}(x)+\theta a_{1}(x)\right) v_{x x}=a_{1}(x) u_{x x}, \\
v(0, x)=0, v(t, 0)=v(t, 1)=0 .
\end{gathered}
$$

Denote by $G(x, \xi ; t)$ the Green's function of the equation (8); then

$$
v(t, x ; \theta)=\int_{0}^{t} \int_{0}^{1} G(x, \xi ; t-\tau) a_{1}(\xi) u_{x x}(\tau, \xi ; \theta) d \xi d \tau .
$$

As $u(t, x ; \theta)$ is the probability of reaching the boundary $x=0$ during the time $t$, then $u_{t} \geqslant 0$ and, therefore, $u_{x x} \geqslant 0$ (evidently $u_{x x} \neq 0$ on the whole interval $(0,1))$. So, $v(t, x ; \theta)>0$ and this proves the lemma.

The derivative of the function $J(\theta)$ can be computed as $\frac{d}{d \theta} J(\theta)=$ $=\int_{0}^{T} \int_{0}^{1} u_{x x}(t, x ; \theta) p(t, x ; \theta) a_{1}(x) d x d t$, where $p(t, x ; \theta)$ satisfies the equation

$$
\begin{gathered}
-\frac{\partial p(t, x ; \theta)}{\partial t}-\frac{\partial^{2}}{\partial x^{2}}\left[a_{0}(x)+\theta a_{1}(x) p(t, x ; \theta)\right]= \\
=2[u(t, x ; \theta)-z(t)] \delta(x-\bar{x}), \\
p(T, x)=0, p(t, 0)=p(t, 1)=0 .
\end{gathered}
$$

5. Instead of the exact value $u(t, \bar{x} ; \theta)$ we have only the approximate value $z_{N}(t)$. Suppose that $z_{N}(t) \rightarrow u\left(t, \bar{x} ; \theta^{*}\right)$ with probability 1 , where $\theta^{*}$ is the true value of the parameter $\theta$.

$$
\text { Let } J_{N}(\theta)=\int_{0}^{T}\left[u(t, \bar{x} ; \theta)-z_{N}(t)\right]^{2} d t \text { and } \min _{\theta \in M} J_{N}(\theta)=J\left(\theta_{N}\right) \text {. }
$$

Lemma 3. Let $\theta^{*} \in M$. Suppose that if $u\left(t, \bar{x} ; \theta_{1}\right)=u\left(t, \bar{x} ; \theta_{2}\right)$, $0 \leqslant t \leqslant T$, then $\theta_{1}=\theta_{2}$. There exists subsequence $\left\{\theta_{N_{t}}\right\}$ such that $\lim \theta_{N_{t}}=\theta^{*}$ with probability 1.

As $\theta_{N_{t}} \in M$, we can find $\left\{\theta_{N_{t}}\right\}$ such that $\theta_{N_{t}} \rightarrow \tilde{\theta}$. By continuity $u\left(t, \bar{x} ; \theta_{N_{t}}\right) \rightarrow u(t, x ; \tilde{\theta})$. As $\lim z_{N_{t}}(t)=u\left(t, \bar{x} ; \theta^{*}\right)$ with probability 1 and $J_{N_{t}}\left(\theta^{*}\right) \rightarrow 0$, then $J_{N_{t}}\left(\theta_{N_{t}}\right) \rightarrow 0$. But then $J_{N_{t}}(\tilde{\theta}) \rightarrow 0$ with probability 1 and $u\left(t, \bar{x} ; \theta^{*}\right)=u(t, \bar{x} ; \tilde{\theta})$. By assumption we conclude that $\theta^{*}=\tilde{\theta}$. 6. We have derived the exact value for the gradient of the function $J(\theta)$. In order to use this expression it is necessary to solve at each 
step two partial differential equations. Now we shall approximate the initial equation by Galerkin's method and then we shall derive the expression for the corresponding gradient. At every step its application will insist on solving two ordinary differential equations. have

Let $U(t, x ; \theta)=u(t, x ; \theta)+(x-1)$, then instead of $(2)$ and (3) we

$$
\begin{gathered}
U_{t}-(\theta, a) U_{x x}=0, \\
U(0, x ; \theta)=x-1, \quad U(t, 0 ; \theta)=U(t, 1 ; \theta)=0 .
\end{gathered}
$$

Let $\left\{f_{n}(x)\right\}, x \in[0,1]$ be the complete set of basis functions, $f_{n}(0)=$ $=f_{n}(1)=0$. We search the approximate solution in the form $U(t, x ; \theta) \approx$ $\approx u_{m}(t, x ; \theta)=\sum_{i=1}^{m} \varphi_{i}(t) f_{i}(x)$. Putting the expression $u_{m}(t, x ; \theta)$ into the equation (9), multiplying the equation $(9)$ by $f_{k}(x)$ and integrating we get the following equation for the function $\varphi_{k}(t)$ :

$$
\begin{aligned}
& \frac{d \varphi_{k}(t)}{d t}=\sum_{i=1}^{n} \sum_{j=1}^{m} \theta_{i} a_{i j}^{k} \varphi_{j}(t), \\
& \varphi_{k}(0)=c_{k}, \quad k=1, \ldots, m .
\end{aligned}
$$

Here $a_{i j}^{k}=\int_{0}^{1} a_{i}(x) f_{j}^{\prime \prime}(x) f_{k}(x) d x$ and $x-1=\sum_{k=1}^{\infty} c_{k} f_{k}(x)$. It is known that $u_{m} \rightarrow U$ uniformly inside the region $D_{T}\left[{ }^{9}\right]$. Let $A_{k}=\left(a_{i j}^{k}\right), \varphi^{\prime}=\left(\varphi_{1}(t), \ldots\right.$ $\left.\ldots, \varphi_{m}(t)\right), c^{\prime}=\left(c_{1}, \ldots, c_{m}\right)$. Denote $A(\theta)=\left(\begin{array}{c}\theta^{\prime} A_{1} \\ \theta^{\prime} A_{m}^{--}\end{array}\right)$. Then the system (12) can be transformed to the form

$$
\begin{aligned}
& \frac{d \varphi}{d t}=A(\theta) \varphi, \\
& \varphi(0)=c .
\end{aligned}
$$

The function $J_{m}(\theta)$ can be expressed as

$$
J_{m}(\theta)=\int_{0}^{T}[(d, \varphi)-\bar{z}(t)]^{2} d t,
$$

where $d^{\prime}=\left(f_{1}(\bar{x}), \ldots, f_{m}(\bar{x})\right), \bar{z}(t)=z(t)+(\bar{x}-1)$. Denote $v_{k}(t)=$ $=\left(\frac{d \varphi_{h}}{d \theta}, \Delta \theta\right), v^{\prime}=\left(v_{1}(t), \ldots, v_{m}(t)\right)$. It is easy to see that

$$
\frac{d v}{d t}=A v+B \Delta \theta, \quad v(0)=0,
$$

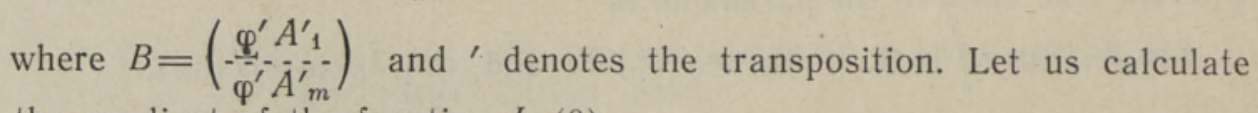
the gradient of the function $J_{m}(\theta)$

$\left(\operatorname{grad} J_{m}(\theta), \Delta \theta\right)=2 \int_{0}^{T}[(d, \varphi)-\bar{z}(t)]\left(d^{\prime} \frac{d \varphi}{d \theta} \Delta \theta\right) d t=2 \int_{0}^{T}[(d, \varphi)-$ $-\bar{z}(t)](d, v) d t$.

Introduce the conjugate system

$$
-\frac{d p}{d t}-A^{\prime} p=2[(d, \varphi)-\bar{z}(t)] d, \quad p(T)=0,
$$


where $A^{\prime}=\left(A^{\prime}{ }_{1} \theta, \ldots, A_{m}^{\prime} \theta\right)$ and $p^{\prime}=\left(p_{1}(t), \ldots, p_{m}(t)\right)$. Multiplying the equation (13) by $v(t)$ and integrating over $[0, T]$ we get $2 \int_{0}^{T}([(d, \varphi)-$ $-\bar{z}(t)] d, v) d t=\int_{0}^{T}\left(\left[-\frac{d p}{d t}-A^{t} p\right], v\right) d t=\int_{0}^{T}\left(p, \frac{d v}{d t}-A v\right) d t=$ $=\int_{0}^{T}(p, B \Delta \theta) d t=\int_{0}^{T}\left(B^{\prime} p, \Delta \theta\right) d t$.

Finally we get

$$
\left(\operatorname{grad} J_{m}(\theta), \Delta \theta\right)=\int_{0}^{T}\left(B^{\prime} p(t), \Delta \theta\right) d t
$$

where $B^{\prime}=\left(A_{1} \varphi, \ldots, A_{m} \varphi\right)$. Formula $(16)$ is the basic formula in various numerical procedures for minimizing the function $J(\theta)$.

7. Let $\min _{\theta \in M} J_{m}(\theta)=J_{m}\left(\theta_{m}\right)$.

Le mma 4. If $\theta^{*} \in M$, then $\lim J_{m}\left(\theta_{m}\right)=J\left(\theta^{*}\right)$.

It is clear that $J_{m}\left(\theta_{m}\right) \leqslant J_{m}\left(\theta^{*}\right) \rightarrow J\left(\theta^{*}\right)$, therefore $\varlimsup_{\lim } J_{m}\left(\theta_{m}\right) \leqslant J\left(\theta^{*}\right)$. Let $\left\{\theta_{m_{l}}\right\}$ be the converging subsequence, $\theta_{m_{t}} \rightarrow \tilde{\theta}$. By Fatou lemma: $\lim J_{m_{t}}\left(\theta_{m_{t}}\right) \geqslant J(\tilde{\theta})$, therefore, $\overline{\lim } J_{m_{t}}\left(\theta_{m_{t}}\right) \leqslant J\left(\theta^{*}\right) \leqslant J(\tilde{\theta}) \leqslant \lim J_{m_{t}}\left(\theta_{m_{t}}\right)$ and $J\left(\theta^{*}\right)=J(\tilde{\theta})$.

\section{REFERENCES}

1. Т о б и а с Т., Изв. АН ЭССР, Физ. Матем., 29, № 4, 432-435 (1980).

2. Тихонов В. И., Выбросы случайных процессов, М., «Наука», 1970.

3. Л в рентьев М. М., Романов В. Г., Шишатский С. П., Некорректные задачи математической физики и анализа, М., «Наука», 1980.

4. У с п енски й А. Б., В кн.: Математическне методы планирования экспернмента, Новосибирск, «Наука», 1981, с. $199-242$.

5. Лионс Ж., Оптимальное управление системами, описываемыми уравнениями с частными производными, М., «Мир», 1972.

6. L i o n s, J. L., In: Lecture Notes in Control and Information Sciences, 1, Springer, Berlin, 1978, p. $11-41$.

7. Polis, M. P., Goodson, R. E., Wozny, M. J., Automatica, 9, № 1, 53-64 (1973).

8. Фрид ман А., Уравнения с частными производными параболнческого типа, М., «Мир», 1968.

9. Ильин А. М., К алашников А. С., Олейник О. А., Успехи мат. наук, 18, вып. 3, 3-146 (1962).

Academy of Sciences of the Estonian SSR,

Received Institute of Cybernetics

Dec. 30,1981

\section{T. TOBIAS}

\section{DIFUSIOONIPROTSESSI IDENTIFITSEERIMINE JA PARABOOLSET TUUPI VÕRRANDITE POOORDULLESANDED}

On uuritud difusiooniprotsessi kordajate hindamist, kui vâatlustulemtisteks on protsessi erinevate trajektooride antud piirkonnast väljumise momendid. On näidatud, et ülesanne on ekvivalentne teatud pöördülesandega paraboolset tüüpi võrrandite teoorias, kus lahendi väärtuste põhjal tuleb leida võrrandi kordajad. Seda pöördülesannet on vaa deldud kui teatud minimeerimisülesancet. On esitatud avaldis sihifunktsionni gradiendi arvutamiseks ning vaadeldud Galjorkini meetodil põhinevat diskretiseerimismeetodit. 


\section{กิ. ТОБИАС}

\section{ИДЕНТИФИКАЦИЯ ДИФФУЗИОННОГО ПРОЦЕССА И ОБРАТНЫЕ ПАРАБОЛИЧЕСКИЕ ЗАДАЧИ}

Рассматривается задача оценивания параметрически заданных коэффициентов диффузионного процесса по наблюдениям на границе заданной области. Показывается, что задача эквивалентна обратным задачам в теории параболических уравнений, коэффициенты в которых требуется определить по значениям решения в определенных точках. Эта задача идентификации рассматривается как задача минимизации. Дается формула для вычисления градиента целевой функции. Рассматривается также метод дискретизации, основанный на методе Галеркина. 